\title{
The double burden of malnutrition: the obesity/ under nutrition paradox, non communicable diseases and the challenge of early prevention public policies
}

\section{Editorial}

Diabetes is a disease that left to its natural evolution will have harmful effects on those who have the disease. Good news are; management has evolved and developed and a better life conditions can be offered to diabetic patients and prevention has reached an important place in the global health priorities, in particular because type 2 diabetes can be prevented through changes in life style that are cost effective and achievable with education, persistence and the right investments. There is no doubt that a non communicable diseases are a global health concern and that obesity and type 2 diabetes have been in the rise in the last decades at an alarming rate. So has been the increase in the risk for the cardiovascular diseases associated. The elevated cost not only economic, but in terms of the deteriorated quality life of those who suffer these diseases is a major topic for scientific, social and policy making discussion more over when concern about productivity and wellbeing of societies is compromised. Also in the last decades, the developing world is facing the increases in this Non Communicable Diseases (NCD) while still dealing with undernutrition and communicable diseases. ${ }^{1,2}$ This has been a complex scenario when addressing the right interventions because at least ideally the aim should be to provide care for those overweight and or obese, compensate those who are undernourished while attending the normal population.

Uauy et al. ${ }^{3}$ statement: "nutritional problems on a global basis are somewhat paradoxical: poor countries mostly affected by undernutrition over the past centuries are presently also showing rising prevalence of obesity and related burden of non communicable diseases" 3 shows the paradox that must be faced by communities all over when experiencing the rise of obesity in conditions that traditionally were accompanied by deficit, while still dealing with undernutrition issues for a part of its population. Many places in the world must deal with this situation better known as: "the double burden of malnutrition". ${ }^{4}$ The demographic and urbanization transition process along with the nutrition transition as a consequence of a different lifestyle with changes in food and physical activity patterns, have reached almost any community of the world, promoting increased adiposity in spite that living conditions might still be precarious, healthy foods might not be equally distributed, hygiene patterns might be rare for some individuals, ${ }^{5}$ while physical inactivity in the raise, was identified in 2010 as the fourth leading factor for global mortality. ${ }^{6}$ All these contributors show that nutritional excess might not be equal to development.

In the light of the new discoveries about early programming of non-communicable diseases, a new approach is ahead: early prevention. Since the publication in 1993 of Barker et al's initial work that proposed the association between undernourishment during
Volume I Issue I - 2014

\author{
Marianella Herrera Cuenca \\ Nutrition and Food Public Policies, CENDES/Central University \\ of Venezuela, South America
}

\begin{abstract}
Correspondence: Marianella Herrera Cuenca, Nutrition and Food Public Policies, CENDES/Central University of Venezuela, Av. Neverí Ed FUNDAVAC, Piso I, South America,Tel +582127535859, Email marianella.herrera@ucv.ve
\end{abstract}

Received: April 26, 2014 | Published: April 27, 2014

pregnancy, low birth weight and the development of metabolic and cardiovascular diseases later in life, as a consequence of the fetal adaptation to undernutrition, a whole new world of research came out to elucidate how early was the origin of diseases. ${ }^{7}$ These statements changed the way that prevention of NCD should be promoted, since low birth weight is a consequence not only of maternal nutrition status during pregnancy but also of the environmental conditions on which pregnancy is taking place. Again many conditions including sociodemographic factors including: poor housing conditions, lack of hygiene, food insecurity, inadequate access to quality water, exposure to contaminants and access to the right and healthy foods, among others, ultimately constitute elements that influence nutrition status of the global population. ${ }^{8}$ Moreover, maternal pre-pregnancy nutrition status is a key factor that somehow predisposes to future health impairments, hers and her child's. ${ }^{8,9}$

Women of child bearing age that are overweight or obese, are likely to gain excessive weight while pregnant and are at risk for post partum weight retention, which makes them, if becoming pregnant again, to start this new pregnancy with a higher Body Mass Index (BMI), during which excessive weight gain, along with other risk factors such as gestational diabetes will lead to alterations in the offspring such as: higher adiposity, fetal macrosomia or even Low Birth Weight ${ }^{9,10}$ If the newborn is female and starts life in poor conditions and is raised obese or undernourished, the vicious cycle of malnutrition begins again. ${ }^{1,9}$ Epigenetic mechanisms allow the physiological plasticity for adaptation to adverse early conditions, in particular to inadequate nutrition, for development ${ }^{11}$ and growth retardation, low height, low velocity for growth, neuro cognitive impairments and increased adiposity during the first years of life are some of the adaptations to be found in the offspring of these mothers ${ }^{12}$

Some other factors will complicate more this vicious cycle: adolescent pregnant which is a common situation in the developing world and even though not as common but still existent in the industrialized world, and teenage mothers when overweight, obese or 
undernourished are at higher risk for adverse perinatal outcomes. ${ }^{13}$ In a low income community from Caracas, Venezuela a study in pregnant women ${ }^{14}$ showed that $26.5 \%$ were clinically undernourished while $21.0 \%$ were overweight or obese, with an increase in undernourishment in pregnant adolescents, in 2010 the raise in the pregnancies of teenage girls in this country continues to be motive for health concern. Because undernourished mothers and obese mothers can lead to Low Birth Weight (LBW) and macrosomic offsprings and make their infants to be at higher risk for cardiovascular diseases in the future, ${ }^{15}$ it is urgent that the exposure to impaired metabolic milieu in utero can be stopped. Not only the lives of newborns will be improved but quality of life for the mother to be will be guaranteed.

Obesity should be prevented as early as possible, since once installed it is hard to reverse and control, this is why in this new perspective, interventions such as controlling gestational weight gain, ensuring adequate sleep in infants and exclusive breast feeding when possible ${ }^{9}$ are key factors to maintain adequate weight during childhood: not excessive, not at deficit. For ameliorating the raise of $\mathrm{NCD}$, in particular obesity and type 2 diabetes, early prevention seems the logical pathway, more over when prevention as previously said, through life style interventions is effective and save the cost of many adverse consequences for health status of the populations. ${ }^{1,9}$ When addressing quality of life and well being of a population for policy making it is important, as stated by FAO to guarantee the right to adequate food and nutrition as well as food security as adequate access to healthy foods in social acceptable ways. ${ }^{16}$ Social programs, in particular the ones involving food subsidy, should promote the intake of healthy nutritious foods such as fruits and vegetables and not only focus on rich, cheap and dense caloric foods as traditional programs have been doing in the past. ${ }^{17}$ Large investments to promote agriculture productivity especially that focused on staple cereals will not necessarily result in a better nutrition if they are not accompanied by investments in health and education services that can be accessed by the disadvantaged people. ${ }^{16}$

Interventions for improving health through life style changes should consider prioritizing the access to nutritious foods and promoting physical activity at the same time for obtaining energy balance of individuals. Then, investments will be made congruent and consistent, together with nutrition education, community participation in social programs, and adequate health care and safe space for physical activity. The previous paragraphs show not only the need for closely monitor maternal nutritional status and well being in general, but the imperative necessity for a public policy that address both extremes of malnutrition when needed: under and over nutrition in pregnant women as an early nutrition prevention along with sexual planning program that consider a life cycle approach. ${ }^{18}$ To invest in a program that promotes exclusive breast feeding, obstetric control and physical activity and that makes emphasis in adequate weight gain during pregnancy will do better than complicated expensive intervention programs in the long term. The health care practitioners community for sure envision the future programs that would work with collaboration from governments, food industry and academia aligned toward population's health and most of all: for the health of future generations.

\section{Acknowledgements}

None.

\section{Conflict of interest}

Author declares that there is no conflict of interest.

\section{References}

1. Harold A. The economic cost of a poor start to life. J Dev Orig Health Dis. 2010;1:19-25.

2. Narayan V, Ali M, Koplan JP. Global Noncommunicable DiseasesWhere the Worlds Meet. NEJM. 2010;363:1196-1198.

3. Uauy R, Garmendia ML, Corvalan C. Addresing the Double Burden of Malnutrition with a Common Agenda. In International Nutrition: Achieving Millenium Goals and Beyond. Nestlé Nutr Inst Workshop. 2014;78:39-52.

4. Tanumhardjo S, Anderson S, Kaufer-Horwitz M, et al. Poverty, Obesity and Malnutrition: An International Perspective Recognizing the Paradox. J Am Diet Assoc. 2007;107(11):1966-1972.

5. Laurentin A, Schnell M, Tovar J, et al. Transición Alimentaria y Nutricional: Entre la desnutrición y la Obesidad. An Venez Nutr. 2007;20(1):47-52.

6. World Health Organization. Global Recommendations on Physical Activity for Health. 2014.

7. Barker DJ, Gluckman PD, Godfrey KM, et al. Fetal nutrition and cardiovascular disease in adult life. Lancet. 1993;341(8850):938-941.

8. Laraia BA, Siega -Riz AM, Gundersen C. Household Food Insecurity is Associated with Self-Reported Pregravid Weight Status, Gestational Weight Gain and Pregnancy Complications. $J$ Am Diet Assoc. 2010;110(5):692-701.

9. Gillman MW and Ludwig DS. How Early Should Obesity Prevention Start? N Engl J Med. 2013;369:2173-2175.

10. Sonneville KR, Rifas-Shiman SL, Oken E, et al. Longitudinal Association of Maternal Attempt to Lose Weight During the Post Partum Period and Child Obesity at age 3years. Obesity. 2011;19(10):2046-2052.

11. Gluckman PD, Hanson MA, Cooper C, et al. Effect of In Utero and Early Life Conditions on Adult Health and Disease. $N$ Engl J Med. 2008;359:61-73.

12. Neufeld LM, Osendarp SJM. Global, Regional and Country Trends in Underweight and Stunting as Indicators of Nutrition and Health of Populations. In International Nutrition: Achieving Millenium Goals and Beyond. Nestlé Nutr Inst Workshop. 2014;78:11-19.

13. Haeri S, Guichard I, Baker AM, et al. The Effect of Teenage Maternal Obesity on Perinatal Outcomes. Obstet Gynecol. 2009;113(21):300-304.

14. Rached I, Azuaje A, Henríquez G. Estado Nutricional en Gestantes de una Comunidad Menos Privilegiada de Caracas. An Ven Nutr. 2002;15(2): 94-104.

15. Black RE, Victora CG, Walker SP, et al. Maternal and Child Undernutrition and Overweight in Low-income and Middle-income countries. Lancet. 2013;382(9890):427-451.

16. Ruel M. Food Security and Nutrition: Linkages and Complementarities Chap 2 in The Road to Good Nutrition. A Global Perspective. Karger. 2013;24-38.

17. Black AP, Brimblecombe J, Eyles H, et al. Food subsidy programs and the health and nutritional status of disadvantaged families in high income countries: a systematic review. BMC Public Health. 2012;12:1099.

18. Johnson DB, Gerstein DE, Evans AE, et al. Preventing Obesity: A life Cycle Perspective. J Am Diet Assoc. 2006;106(1): 97-102. 